\title{
Profile and feto-maternal outcomes of pregnant women with thyroid dysfunction: a prospective study from South India
}

\author{
Mamatha Shivanagappa $^{1}{ }^{*}$, Mahesh Mahadevaiah $^{2}$, Gayathri Rao $^{1}$, Triveni Kondareddy ${ }^{1}$
}

\begin{abstract}
${ }^{1}$ Department of Obstetrics and Gynecology, ${ }^{2}$ Department of General Medicine, JSS Medical College, JSS University, Mysore, Karnataka, India
\end{abstract}

Received: 16 October 2016

Accepted: 22 October 2016

\section{*Correspondence:}

Dr. Mamatha Shivanagappa,

E-mail: mamathamahesh106@gmail.com

Copyright: $\odot$ the author(s), publisher and licensee Medip Academy. This is an open-access article distributed under the terms of the Creative Commons Attribution Non-Commercial License, which permits unrestricted non-commercial use, distribution, and reproduction in any medium, provided the original work is properly cited.

\section{ABSTRACT}

Background: There is an increasing trend in the occurrence of thyroid disorders in pregnant women. Hyperthyroidism occurs in $0.2 \%-0.3 \%$ and can cause foetal loss, growth retardation, pre-eclampsia, and preterm delivery. Subclinical hyperthyroidism is found in 1.5 to $1.7 \%$ but has not been associated with adverse outcomes. Incidence of overt hypothyroidism ranges from 0.2 to $2.5 \%$ and Subclinical hypothyroidism from 2-7\%.There is sparse data regarding this from South India.

Methods: This was an observational, hospital based study. 1000 inpatients JSS Hospital, Mysore between November 2011 to July 2013 were studied. Included were inpatients of antenatal ward irrespective of age, parity and their gestational age. Excluded were unbooked cases in obstetric emergencies or cases in active labour. TSH estimation was done for all. If abnormal, $\mathrm{T} 3$ and $\mathrm{T} 4$ were done.

Results: With respect to thyroid status $816(81.6 \%)$ were euthyroid, 44 (4.4\%) hypothyroid, $126(12.6 \%)$ subclinical hypothyroidism and $14(1.4 \%)$ were hyperthyroid. $53(5.3 \%)$ had irregular cycles $57(5.7 \%)$ had diabetes, 98 (9.8\%) hypertension. $11.4 \%$ had diabetes in hypothyroid state had 5.8\% had diabetes in euthyroid state. Hypertension in hypothyroid state was 5 out of 44 (11.4\%), in those with subclinical hypothyroid state it was 13 out of $126(10.3 \%)$ and euthyroid state was $9.8 \%$. Significantly more patients in hypothyroid state needed cesarean section. The fetal anomalies detected were 4 cases of ventriculomegaly, 2 cases of hydrocephalus, 3 spina bifida, 4 cases of renal anomalies of which 1 was renal agenesis and 3 were polycystic kidneys.

Conclusions: This study showed significant association between uncontrolled hypothyroidism and adverse fetomaternal outcome. Abnormal thyroid status was significantly associated with hypertension, diabetes, anaemia and fetal anomalies.

Keywords: Gestation, Hypothyroidism, Hyperthyroidism, Thyroid disorders

\section{INTRODUCTION}

Thyroid disease is the second most common endocrine dysfunction in women of child bearing age (diabetes being the first). ${ }^{1,2}$ Thyroid disease during pregnancy is challenging to diagnose because of the nonspecific symptoms and the hypermetabolic state of normal pregnancy. ${ }^{3}$ It has long been recognized that maternal thyroid hormone excess or deficiency can influence the outcome of mother and fetus at all stages of pregnancy as well as interfere with ovulation and fertility. ${ }^{4}$ Maternal hypothyroidism is a common occurrence during pregnancy with overt and subclinical hypothyroidism being reported in about 0.2 and $2.3 \%$ of pregnancy respectively. ${ }^{5-7}$ It is associated with foetal loss, pregnancy induced hypertension preterm delivery placental abruption and reduced intellectual function in the offspring. ${ }^{8,9}$

Overt maternal hyperthyroidism is less commonly observed in $0.2 \%$ to $2.5 \%$ of pregnancies and can cause foetal loss, IUGR, pre-eclampsia, preterm delivery. ${ }^{10-12}$ 
Mild or subclinical hyperthyroidism is found in $1.5 \%$ to $1.7 \%$ and has not been specifically associated with adverse pregnancy outcome. This study was hence taken up to know the magnitude of thyroid disorders in pregnancy in inpatients of JSS. Hospital, Mysore and to assess the outcome of pregnancy in those with thyroid dysfunction.

\section{METHODS}

This was an observational, hospital based, time bound study. 1000 inpatients of antenatal wards in JSS Hospital (a tertiary care teaching hospital, Mysore, South India) were taken up for the study. The study period was between November 2011 to July 2013. Random sampling was followed. Inpatients of antenatal ward irrespective of age, parity and gestational age were taken up. Excluded from the study were unbooked cases in obstetric emergencies or those in active labour. TSH level estimation was done by chemiluminisense immunoassay method for all the patients. If abnormal $(<0.3$ or $>3 \mu \mathrm{IU} / \mathrm{ml}$ ) $\mathrm{T} 3$ and $\mathrm{T} 4$ was done. The patients were classified accordingly as euthyroid, hypothyroid, hyperthyroid, subclinical hyperthyroid and subclinical hyperthyroid.

\section{RESULTS}

There were 1000 subjects. The age ranged from less than 20 to more than 36. Majority of the subjects 482 (48.2\%) were in the age range of between 21-25 years (Table 1).

Table 1: Age distribution.

\begin{tabular}{|lll|}
\hline Age in years & Frequency & Percent \\
\hline$<20$ & 207 & 20.7 \\
\hline $21-25$ & 482 & 48.2 \\
\hline $26-30$ & 254 & 25.4 \\
\hline $31-35$ & 43 & 4.3 \\
\hline$>36$ & 13 & 1.3 \\
\hline Total & 999 & 100.0 \\
\hline
\end{tabular}

$464(46.4 \%)$ were primigravida $322(32.2 \%)$ were gravida two, $144(14.4 \%)$ were gravida three, $48(4.8 \%)$ were gravida four and $18(1.8 \%)$ were grand-multi (Figure 1).

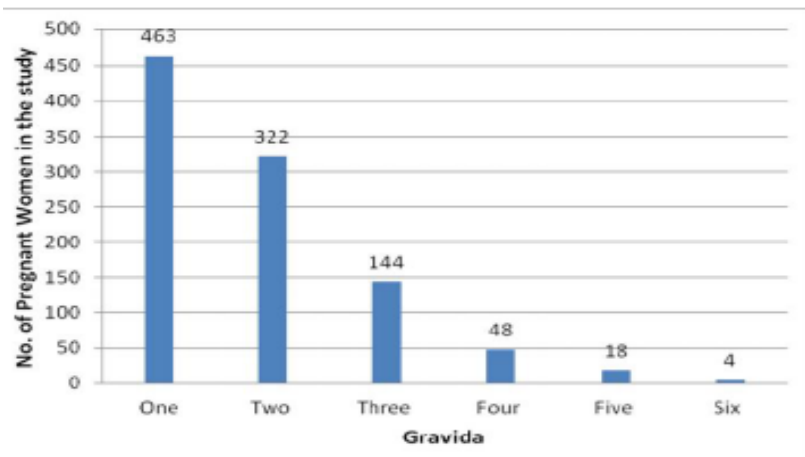

Figure 1: Gravida status of the subjects.
As regards presence of associated co-morbidities, 57 $(5.7 \%)$ were diabetic and $98(9.8 \%)$ were hypertensive (Figure 2).

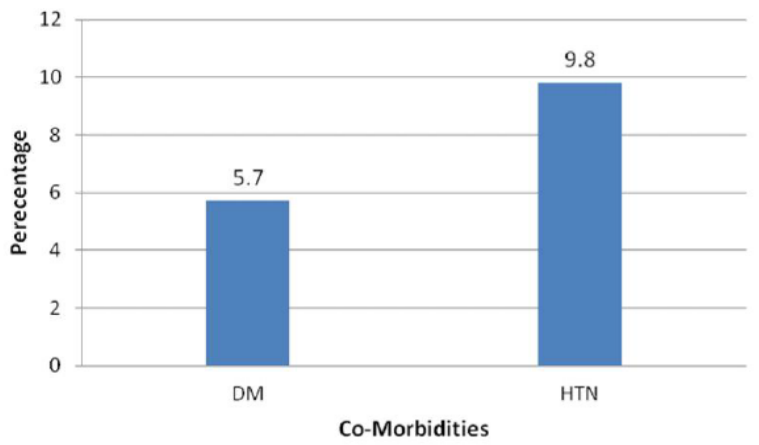

Figure 2: Depicting co-morbidities.

With respect to Menstrual history 53 (5.3\%) had irregular cycles and 947 (94.7\%) had regular cycles. With regard to haemoglobin level of study participants, $4(0.4 \%)$ had $<5 \mathrm{gm} \%, 17(1.7 \%)$ had 6-7gm\%, 237 (23.7\%) had 7.1$10 \mathrm{gm} \%$ (Figure 3).

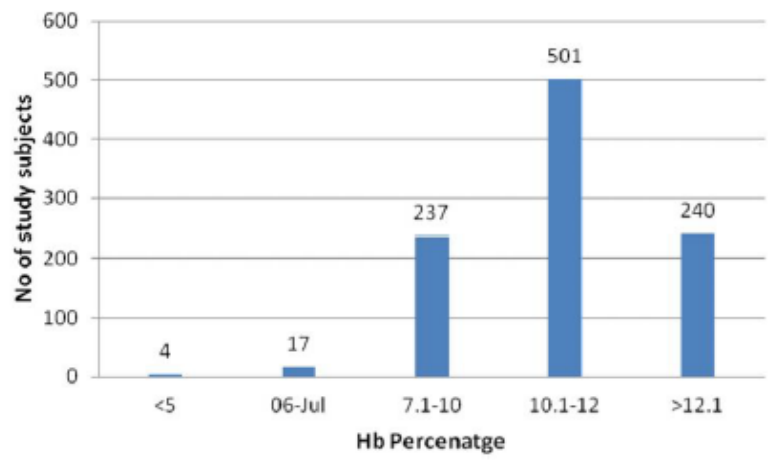

Figure 3: Depicting haemoglobin levels of study participants.

With regard to Thyroid Profile $816(81.6 \%)$ were euthyroid, 44 (4.4\%) were hypothyroid, 126 (12.6\%) were subclinical hypothyroid and $14(1.4 \%)$ hyperthyroid 7 (Table 2).

Table 2: Depicting thyroid status.

\begin{tabular}{|lll|}
\hline Thyroid profile & Frequency & Percent \\
\hline Euthyroid & 815 & 81.6 \\
\hline Hypothyroid & 44 & 4.4 \\
\hline Sub hypothyroid & 126 & 12.6 \\
\hline Hyperthyroidism & 14 & 1.4 \\
\hline Total & 999 & 100.0 \\
\hline
\end{tabular}

The details regarding type of delivery were as follows. $365(62.5 \%)$ had LSCS, $209(35.8 \%)$ had vaginal delivery and $10(1.7 \%)$ had outlet=forceps (Table 3). With respect to Menstrual cycle and thyroid status $7.1 \%$ 
had irregular cycles in subclinical hypothyroid state, in euthyroid state $5.2 \%$ had irregular cycles (Table 4).

Table 3: Depicting type of delivery.

\begin{tabular}{|lll|}
\hline & Frequency & Percent \\
\hline Normal vaginal & 209 & 35.8 \\
\hline LSCS & 365 & 62.5 \\
\hline Forceps & 10 & 1.7 \\
\hline Total & 584 & 100 \\
\hline
\end{tabular}

Table 4: Depicting thyroid status and menstrual cycles.

\begin{tabular}{|llll|}
\hline & Total & \multicolumn{2}{l|}{ Irregular } \\
\hline Euthyroid & 815 & No & \% \\
\hline Hypothyroid & 44 & 42 & 5.2 \\
\hline Sub hypothyroid & 126 & 9 & 2.3 \\
\hline Hyperthyroidism & 14 & 1 & 7.1 \\
\hline Total & 999 & 53 & 7.1 \\
\hline
\end{tabular}

Chi-square test, $\mathrm{p}=0.7$

With reference to diabetes mellitus and thyroid status $11.4 \%$ had diabetes in hypothyroid state, 5.8\% had diabetes in euthyroid (Figure 4).

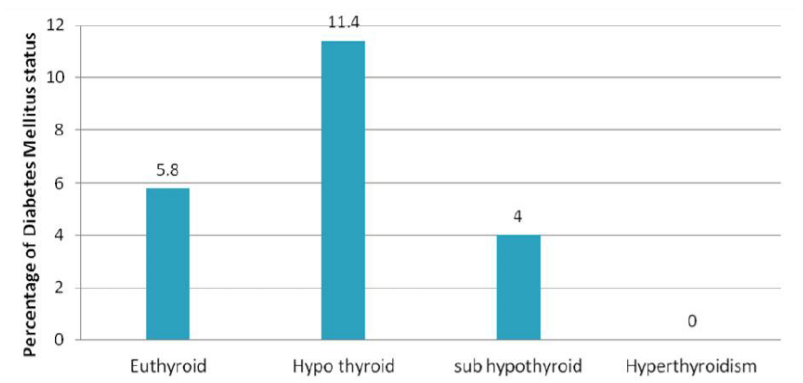

Figure 4: Depicting diabetes mellitus and thyroid status.

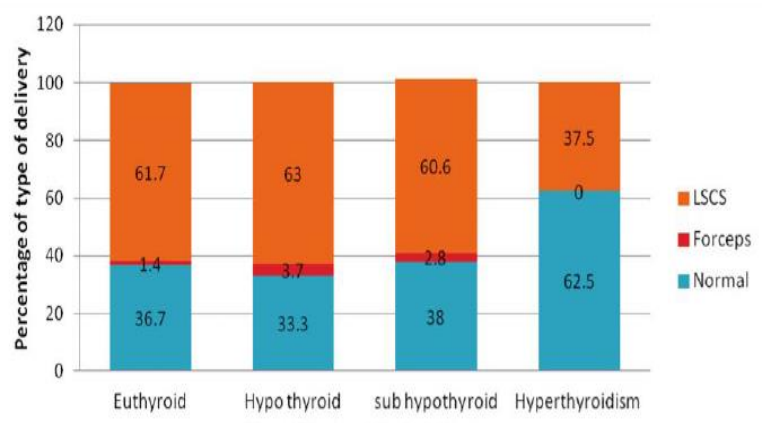

Figure 5: Depicting mode of delivery and thyroid status.

As regards hypertension and thyroid status, $11.4 \%$ had hytertension in hypothyroid state, $10.3 \%$ had hypertension in subclinical hypothyroid state, whereas only $9.8 \%$ in euthyroid state. With reference to mode of delivery and thyroid status our study showed that need for Caesarian Section was significantly more in those with hypothyroid status (Figure 5).

Table 5: Thyroid status and anemia.

\begin{tabular}{|llll|}
\hline & Total & Anemia \\
\cline { 2 - 4 } & & No & \% \\
\hline Euthyroid & 815 & 212 & 26.0 \\
\hline Hypothyroid & 44 & 10 & 22.7 \\
\hline Sub hypothyroid & 126 & 35 & 27.8 \\
\hline Hyperthyroidism & 14 & 1 & 7.1 \\
\hline Total & 999 & 258 & 25.8 \\
\hline
\end{tabular}

Chi-square test, $\mathrm{p}=0.4$

Outcome of delivery and thyroid status Out of 594 delivered, $7.4 \%$ in hypothyroid status had anomalies. The following anomalies were detected. 4 cases of ventriculomegaly, 2 cases of hydrocephalus, 3 spina bifida, 4 cases of renal anomalies of which 1 was renal agenesis and 3 were polycystic kidneys. Tracheo esophageal fistulas absent nasal bone diaphragmatic hernia were the other anomalies (Table 6).

Table 6: Outcome of delivery and thyroid status.

\begin{tabular}{|lllll|}
\hline & \multirow{2}{*}{ Total } & \multicolumn{2}{c|}{ Anamoly } & P \\
\cline { 3 - 5 } & & No & \% & \\
\hline Euthyroid & 488 & 15 & 3.1 & 0.4 \\
\hline Hypothyroid & 27 & 2 & 7.4 & 0.2 \\
\hline Sub hypothyroid & 71 & 2 & 2.8 & 0.8 \\
\hline Hyperthyroidism & 8 & 0 & 0.0 & 0.6 \\
\hline Total & 594 & 19 & 3.2 & \\
\hline
\end{tabular}

\section{DISCUSSION}

Excess or deficiencies of maternal thyroid hormones have been associated with adverse health outcomes for both mother and child. The study of Moreno Reyes et al showed $15.3 \%$ of pregnancies having thyroid disorders and Raverot $\mathrm{V}$ et al showed $11 \%$ of pregnancies having thyroid disorders. $^{13,14}$ In our study $18.4 \%$ had thyroid disorders. This is a non significantly higher incidence compared to the above two. The study of Wilson et al showed $8.5 \%$ of hypertension in euthyroid and Leung AS et al showed $7.6 \%$ and our study had $9.8 \%$ of hypertension in euthyroid. ${ }^{15,16}$ The results of our study are in conformity with previous studies done on different populations. The study of Leung AS et al showed $25.6 \%$ of anaemia in thyroid disorders, Davis et al showed $29.2 \%$, Garner et al shows $24.3 \%$, Colatrella et al showed $28 \%$ and our study had $27.8 \%$ incidence of anaemia in those with thyroid disorders. ${ }^{17-19}$ Once again the results were in agreement with those of previous studies in other geographical regions. Study of Haddow SE showed 5.9\% of anomalies in thyroid disorders, Abalovich M showed $6.3 \%$ and our study had $7.4 \%$ of anomalies in those with thyroid disorders. $^{20,21}$ Overall the results of our study were similar to those observed in various other studies. 
The limitation of this study is the small sample size and hence further studies with larger number of subjects are needed.

\section{CONCLUSION}

This study has shown significant association between uncontrolled hypothyroidism and adverse fetomaternal outcome. There was a significant correlation between the thyroid status and prevalence hypertension, diabetes, anaemia, anomalies in our study. Central nervous anomalies and renal anomalies were more in hypothyroid state. TSH should be included in the list of routine investigations done in all antenatal women in first trimester

\section{ACKNOWLEDGEMENTS}

We wish to extend our grateful thanks to Dr Chandrashekar AP, Head of the Department of Obstetrics and Gynecology, JSS Hospital Mysore for his overall guidance and to Dr Lancy D'Souza Professor, University of Mysore, for help in statistical analysis. Special thanks to Miss Madhumitha. M, Second Year Medical Student JSS Medical College, Mysore for assistance in manuscript preparation and proof reading.

\section{Funding: No funding sources}

Conflict of interest: None declared

Ethical approval: The study was approved by the Institutional ethical committee of JSS Medical College

\section{REFERENCES}

1. Casey BM, Leveno KJ. Thyroid disease in pregnancy. Obstet Gynecol. 2006;108:1283-92.

2. Stagnaro GA. Overt Hyperthyroidism and Hypothyroidism during pregnancy. Clin Obstet Gynaecol. 2011;54(3):478-82.

3. Negro R, Schwartz A. Detection and treatment of thyroid in pregnancy. J Clin Endocrinol Metab. 2010;95(4):1699-707.

4. Thanuja PM, Rajgopal K, Sadiqunnisa. Thyroid dysfunction in pregnancy and maternal outcome. IOSR Journal of Dental and Medical Sciences. 2014;(13):115.

5. Casey BM, Dashe JS, Wells CE, McIntire DD, Byrd EW, Leveno KJ. Subclinical Hypothyroidism and pregnancy outcomes. Obstet Gynecol. 2005;105:23945 .

6. Sahu MT, Das V, Mittal S, Agarwal A, Sahu M. Overt and subclinical thyroid dysfunction among Indian pregnant women and its effect on maternal and fetal outcome. Archives of Gynecology and Obstetrics. 2010;281(2):215-20.

7. Abalovich M, Gutierrex S, Alcaraz G, Maccallini G, Garcia A, Levalle O. Overt and subclinical hypothyroidism complicating pregnancy. Thyroid. 2002; 12:63-68.
8. Mannisto T, Vaarasmaki M. Thyroid dysfunction and maternal morbidity.J Clin Endocrinol Metab. 2010;95(3):1084-94.

9. Millar LK, Wing DA. Low birth weight and preeclampsia in pregnancies complicated by hyperthyroidism. Obstet Gynecol. 1994;84(6):946-48.

10. Baneerjee S. Thyroid Disorders in Pregnancy. Special issue on Indian thyroid guidelines 2011; J of the Assoc of Physicians of India (JAPI). http://www.japi.org/thyroid_special_jan_issue_2011/art icle_07.html

11. Nambiar V, Jagtap VS, Sarathi V, Lila AR, Kamalanathn S, Bandgar TR. Prevalance and impact of thyroid disorders on maternal outcome in Asian Indian, Pregnant women. J Thyroid Res. 2011:429097.

12. Mestman JH. Hyperthyroidism in pregnancy. Endocrinol Metab Clin North Am. 1998;27:127-49.

13. Moreno-Reyes R, Glinoer D, Van Oyen H, Vandevijvere S. High prevalence of thyroid disorders in pregnant women in a mildly iodine-deficient country: a population-based study. J Clin Endocrinol Metab. 2013 Sep;98(9):3694-701.

14. Raverot V, Bournaud C, Sassolas G, Orgiazzi J, Claustrat F, Gaucherand P. Pregnant French women living in the Lyon area are iodine deficient and have elevated serum thyroglobulin concentrations. Thyroid. 2012 May;22(5):522-8.

15. Wilson KL, Casey BM, McIntire DD, Halvorson LM, Cunningham FG. Subclinical thyroid disease and the incidence of hypertension in pregnancy. Obstet Gynecol. 2012 Feb;119(2 Pt 1):315-20.

16. Leung AS, Millar LK, Koonings PP. Perinatal outcome in hypothyroid pregnancies. Obstet Gynecol. 1993;81:349-53.

17. Davis LE, Lucas MJ, Hankins GDV. Thyrotoxicosis complicating pregnancy. Am J Obstet Gynecol. 1989;160:63-70.

18. Garner PR, Burrow GN. Medical complications during pregnancy. In: Burrow G, Duffy T, Copel JA, editors. Pituitary and adrenal disorders of pregnancy. 6th edition. Philadelphia (PA): WB Saunders Company; 2004:16.

19. Colatrella A, Loguercio V, Mattei L, Trappolini M, Festa C, Stoppo M, et al. Hypertension in diabetic pregnancy: impact and long-term outlook. Best Practice \& Research Clinical Endocrinology and Metabolism. 2010;24:635-51.

20. Haddow SE, Palomaki GE, Allan WC. Maternal thyroid deficiency during pregnancy and subsequent neuropsychological development of the child. N Eng J Med. 1999;341:549-55.

21. Abalovich M, Gutierrex 5, Alcaraz G. Overt, and subclinical hypothyroidism complicating pregnancy. Thyroid. 2002;12:63-8.

Cite this article as: Mamatha S, Mahesh M, Gayathri R, Triveni K. Profile and feto-maternal outcomes of pregnant women with thyroid dysfunction: a prospective study from South India. Int J Reprod Contracept Obstet Gynecol 2016;5:4132-5. 